\title{
Improvement of performances of complex non-platinum electrode materials for hydrogen evolution
}

\author{
P. Paunovića, ${ }^{a}$, O. Popovski ${ }^{b}$, A. Dimitrov ${ }^{a}$, D. Slavkov ${ }^{\text {a }}$, \\ E. Lefterova ${ }^{\mathrm{c}}$, S. Hadži Jordanov ${ }^{\mathrm{a}}$ \\ a Faculty of Technology and Metallurgy, University "Sts. Cyril and Methodius" Skopje, \\ Rudjer Boskovic 16, 1000 Skopje, The Former Yougoslav Republic of Macedonia \\ b Military Academy “Gen. Mihailo Apostolski”, Skopje, The Former Yougoslav Republic of Macedonia \\ ${ }^{\mathrm{c}}$ Institute of Electrochemistry and Energy Systems, Bulgarian Academy of Science, Sofia, Bulgaria \\ Received 9 November 2005; received in revised form 16 December 2005; accepted 22 December 2005 \\ Available online 19 May 2006
}

\begin{abstract}
Structural and electrochemical characteristics of hypo-hyper d-electrocatalytic materials aimed for preparation of electrodes for hydrogen evolution were studied and modified in order to improve their performances. All studied materials were of general composition $10 \% \mathrm{Ni}+18 \%$ $\mathrm{TiO}_{2}+\mathrm{C}$.

All materials were prepared of amorphous or crystalline $\mathrm{TiO}_{2}$, crystalline Ni or NiCo $(10-20 \mathrm{~nm})$ and Vulcan XC-72, by sol-gel procedure.

Both, material's intrinsic catalytic activity and surface area were affected by applied modifications. As a result, the electrocatalytic activity was improved, e.g. transformation of $\mathrm{TiO}_{2}$ into anatase form lowers the HER overpotential for $60 \mathrm{mV}$. Introduction of MWCNTs was even more effective, lowering $\eta$ for $120 \mathrm{mV}$. Co addition to metallic phase lowers $\eta$ for utmost $195 \mathrm{mV}$.

Combined modification of $\mathrm{TiO}_{2}$ and carbon substrate lowers $\eta$ for $145 \mathrm{mV}$, while the complete modification of all three catalyst's components was the most effective with $230 \mathrm{mV}$ decrease of overpotential.
\end{abstract}

(C) 2006 Elsevier Ltd. All rights reserved.

Keywords: Hydrogen evolution; Hypo-hyper d-electrocatalysts; Non-platinum metals

\section{Introduction}

Selection of electrode materials for industrial electrocatalysis processes is not at all an easy task. The conflict of technical and economical issues is evident: the best performing electrocatalysts as, e.g. Pt, Pd, Ru are expensive, while the cheaper substituents using less noble metals as, e.g. Ni, Co, etc. suffer of corrosion, passivation or similar problems.

The need for active, stable and cheaper electrocatalysts motivated intensive research, and resulted in development of multicomponent catalysts. It started with combining the most active precious metals, as $\mathrm{Pt}-\mathrm{Pd}$ or $\mathrm{Ir}-\mathrm{Re}$ [1], but the resulting synergetic effect did not satisfy the expectations. Latter on, based on theoretical analysis given by Brewer [2], Jakšić et al. [3], the efforts were oriented towards combining nonprecious met-

\footnotetext{
* Corresponding author. Tel.: +389 23034 392; fax: +389 23034392.

E-mail address: pericap@ian.tmf.ukim.edu.mk (P. Paunović).
}

als. In the early stages of this research, intermetallic Mo-Co alloys were prepared with activity even superior to that of the individual metals of the platinum group. For hydrogen evolution/reduction reaction it was predicted and proved that combination of d-metals with dissimilar electronic character exhibits pronounced synergetic effect [4]. As a result, combination of hyper d-electronic transition metals (having proper individual catalytic activity) with hypo d-electronic transition metals (poor catalysts as individual metals) become subject of scientific and technical interest. A "new era" of modern electrocatalysis was opened.

The partners in these multicomponent systems could be in both, elemental or valence state as oxides, sulphides and phosphides being the most frequent compounds. A number of combinations of metals in elemental or valence state were used in the multicomponent systems, as grouped in Table 1 .

In cases when both components are in metallic state (group 1), intermetallic compound of the general composition $A_{x} B_{y}$ are formed. In some cases solid-state solutions or mixtures do 
Table 1

Typical hypo-hyper d-intermetallic electrocatalysts

\begin{tabular}{|c|c|}
\hline Type of hypo-hyper d-electrocatalyst & Examples \\
\hline (I) Intermetallic catalysts & $\mathrm{Mo}-\mathrm{Co}, \mathrm{MoPt}_{3}, \mathrm{MoNi}_{3}, \mathrm{MoFe}_{3}, \mathrm{LaCo}_{5}, \mathrm{Ti}_{1-x} \mathrm{Ni}_{x}$ (Tiney-Ni), Ni-Co-Mo, Ni-Zr, Co-Zr, etc. \\
\hline (II) Sulfides, Phosphides & $\mathrm{Ni}-\mathrm{W}-\mathrm{S}, \mathrm{Ni}-\mathrm{W}-\mathrm{P}, \mathrm{Fe}-\mathrm{Ni}-\mathrm{P}$, etc. \\
\hline (III) Catalysts based on Raney-Ni & $\mathrm{Ni}-\mathrm{Al}-\mathrm{Ti}, \mathrm{Ni}-\mathrm{Al}-\mathrm{Mo}, \mathrm{Ni}-\mathrm{Al}-\mathrm{Cr}, \mathrm{Ni}-\mathrm{Zn}-\mathrm{Ti}, \mathrm{Ni}-\mathrm{Zn}-\mathrm{Mo}$, etc. \\
\hline (IV) Mixed oxides & $\mathrm{TiO}_{2}-\mathrm{RuO}_{2}, \mathrm{TiO}_{2}-\mathrm{IrO}_{2}, \mathrm{Ru}_{x} \mathrm{Ti}_{1-x} \mathrm{O}_{2}, \mathrm{RuO}_{2}-\mathrm{IrO}_{2}$, etc. \\
\hline (V) Hypo oxide-hyper metal & $\mathrm{Pt}-\mathrm{TiO}_{2}, \mathrm{Pt}-\mathrm{Ru}-\mathrm{WO}_{3}, \mathrm{Ni}-\mathrm{V}_{2} \mathrm{O}_{5}$, etc. \\
\hline
\end{tabular}

exist. The most representative examples of this group are systems that contain titanium and nickel, $\mathrm{Ti}_{1-x} \mathrm{Ni}_{x}$ ("Tiney-Ni" electrodes) possessing both high surface area and high catalytic activity [5]. In opposite case, when both components are in combined state, usually sulphides or phosphides of hypo and hyper d-metals are present (group II). They are of amorphous character, with well-developed surface area, thus adsorbing/absorbing more hydrogen than pure $\mathrm{Ni}$ does. As a consequence, their activity is up to 10 times than corresponding of activated $\mathrm{Pt}$ and even 250 times than corresponding of metallic nickel [6]. In group III the hyper d-component is in combined state, while the hypo one is in metallic state. The hyper d-component is a Raney-Ni alloy (alloy of $\mathrm{Ni}$ with a metal that is easily leachable in alkaline solution, as, e.g. $\mathrm{Al}$ or $\mathrm{Zn}$ ). After leaching is completed, catalysts with surface area 1000-12,000 times than in case of pure Ni were referred to form [7]. A special case when both components are present as oxides (usually $\mathrm{TiO}_{2}$ in combination with $\mathrm{RuO}_{2}$, or $\mathrm{RuO}_{2}$ combined with $\mathrm{IrO}_{2}$ and nonstochiometric $\mathrm{Ru}_{x} \mathrm{Ti}_{1-x} \mathrm{O}_{2}$, group IV) [8-11]. In group $\mathrm{V} \mathrm{d}$-component is metallic state (as metal or alloy, e.g. Ni, Pt, Co, Co-Ni, Pt-Ru, etc.), while the hypo d-component is an oxide, e.g. $\mathrm{TiO}_{2}, \mathrm{WO}_{3}$, $\mathrm{TiO}_{2}-\mathrm{WO}_{3}$, etc. [12-14].

Multicomponent catalysts of group V were subject of interest in this study. $\mathrm{Ni}$ and $\mathrm{NiCo}$, respectively, were used as hyper $\mathrm{d}$ phase, while $\mathrm{TiO}_{2}$ was used as hypo d-phase.

\section{Experimental}

The specified catalysts were prepared by sol-gel procedure simplified in some parts by the present authors. In the first stage, in order to deposit $\left(\mathrm{TiO}_{2}\right)$ onto carbon substrate, Ti-isopropoxide (Aldrich, 97\%) was added into dispersed Vulcan XC-72 (Cabot Corp., Boston, MA, USA) in anhydrous ethanol. To provide hydrolysis to $\mathrm{Ti}(\mathrm{OH})_{4}$, small amount of $1 \mathrm{M} \mathrm{HNO}_{3}$ was added. This mixture was evaporated at $60^{\circ} \mathrm{C}$ with continuous intensive stirring until fine nano-structured powder of catalyst support was obtained. Further, individual or mixed Me-2,4-pentaedionate (Alfa Aesar, Johnson Matthey, $\mathrm{GmbH}, \mathrm{Me}=\mathrm{Co}$ or $\mathrm{Ni}$ ) was dissolved in absolute ethanol. This solution was added into dispersed catalyst support in anhydrous ethanol. The evaporation was carried out under the same conditions as above. The aim of this operation is to graft the metal-hyper phase onto catalyst support. To decompose both $\mathrm{Ti}(\mathrm{OH})_{4}$ to $\mathrm{TiO}_{2}$ and the residual amount of oraganometallics, the powder was heated for $2 \mathrm{~h}$ at $250{ }^{\circ} \mathrm{C}$ in the atmosphere of $\mathrm{H}_{2}+\mathrm{N}_{2}$. The produced basic catalyst is of composition: $10 \% \mathrm{Ni}+18 \% \mathrm{TiO}_{2}+$ Vulcan XC-72. To determine synergetic effect of this hypo-hyper d-combination, corresponding $\mathrm{Ni}$ catalyst was deposited only on Vulcan $\mathrm{XC}-72$

In order to improve catalytic activity of basic catalyst, all components were modified separately: (i) hypo d-phase- $-\mathrm{TiO}_{2}$ was thermally treated at $480^{\circ} \mathrm{C}$, (ii) multiwall carbon nanotubes (MWCNTs, Guangzhou Yorkpoint Energy Company, China) were used instead of Vulcan XC-72 and (iii) Co was added into hyper d-metallic phase. Further, the basic catalyst was modified on the whole. The composition of investigated electrocatalysts is given in Table 2 .

Produced catalyst powders were further used for preparing porous electrodes for hydrogen evolution reaction. Electrodes aimed for three-phase operation (solid electrode, liquid electrolyte and $\mathrm{H}_{2}$ gas as product) were prepared by hot pressing at $300{ }^{\circ} \mathrm{C}$ with the back layer of carbon black acetylene + PTFE and the front layer of the catalyst + PTFE [15]. Electrochemical investigations were performed using AMEL equipment (Function Generator AMEL 568, Potentiostate/Galvanostate 2053 and software package SOFTASSIST 2.0). The counter electrode was of platinum wire and the reference electrode $-\mathrm{Hg} / \mathrm{HgO}$. The electrolyte was an aqueous solution of 3.5 M KOH (p.a., Merck) at room temperature.

In order to identify the changes produced by the applied modifications, several spectroscopic and structural methods for determination of structural and surface changes were employed. XRD and SEM techniques were used for determining structural characteristics of the catalysts. XRD measurement was carried out on X-Ray diffractometer Philips APD 15, with $\mathrm{Cu}$ $\mathrm{K} \alpha$ radiation, while SEM observation was on Scanning Electron Microscope JEOL, model JEM 200 CX. To determine the level of hypo-hyper d-interaction $\left(\mathrm{TiO}_{2} / \mathrm{Ni}\right)$ infrared spectroscopy was employed, using FT-IR spectrometer, model Bruker Vector 22. A presence of surface valence-state phases of the catalyst's components was determined by XPS spectroscopy, ESCALAB MK II, VG Scientific, England, using Al K $\alpha$ radiation. The ratio

Table 2

Composition of electrocatalysts prepared in this study

\begin{tabular}{llll}
\hline Sample no. & $\begin{array}{l}\text { Hypo oxide } \\
\text { d-phase }(18 \%)\end{array}$ & $\begin{array}{l}\text { Carbon } \\
\text { substrate }(72 \%)\end{array}$ & $\begin{array}{l}\text { Hyper metal } \\
\text { d-phase }(10 \%)\end{array}$ \\
\hline 1 & $\mathrm{TiO}_{2}\left(250^{\circ} \mathrm{C}\right)$ & Vulcan XC-72 & $\mathrm{Ni}$ \\
2 & - & Vulcan XC-72 & $\mathrm{Ni}$ \\
3 & $\mathrm{TiO}_{2}\left(480^{\circ} \mathrm{C}\right)$ & Vulcan XC-72 & $\mathrm{Ni}$ \\
4 & $\mathrm{TiO}_{2}\left(250^{\circ} \mathrm{C}\right)$ & MWCNTs & $\mathrm{Ni}$ \\
6 & $\mathrm{TiO}_{2}\left(480^{\circ} \mathrm{C}\right)$ & MWCNTs & $\mathrm{Ni}$ \\
5 & $\mathrm{TiO}_{2}\left(250^{\circ} \mathrm{C}\right)$ & Vulcan XC-72 & $\mathrm{NiCo}$ \\
7 & $\mathrm{TiO}_{2}\left(480^{\circ} \mathrm{C}\right)$ & MWCNTs & $\mathrm{NiCo}$ \\
\hline
\end{tabular}

${ }^{a}$ In this sample there is not $\mathrm{TiO}_{2}$, so the content of Vulcan XC-72 is $90 \%$. 


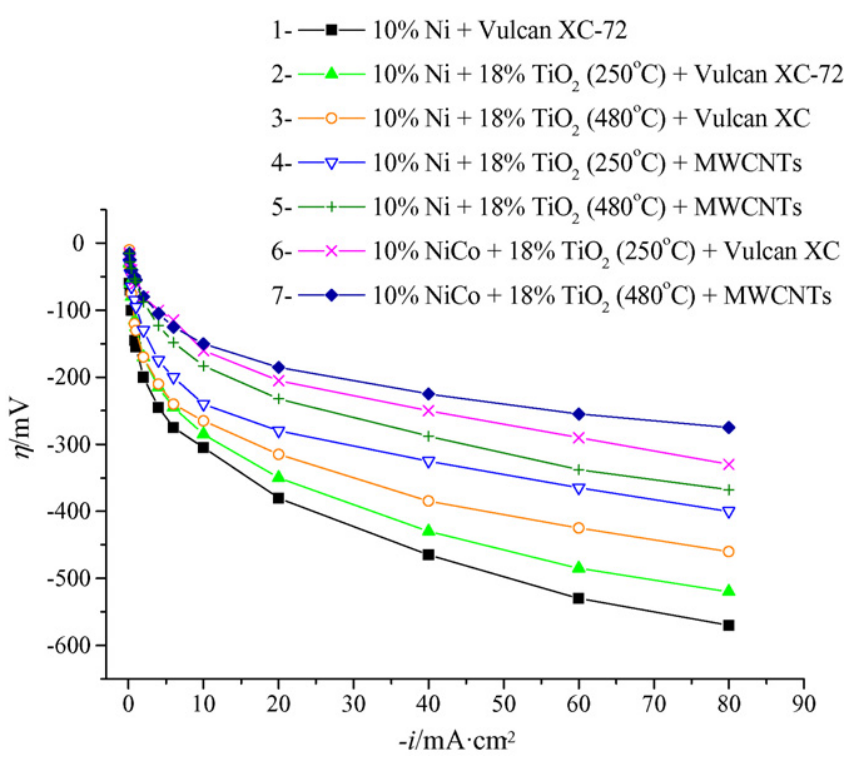

Fig. 1. Polarization curves of investigated hypo-hyper d-electrocatalysts.

of real versus geometric surface area of the electrodes was determined as a quotient of catalyst's double layer capacity $C_{\mathrm{dl}}$ versus double layer capacity $C_{\text {dlo }}$ of pure oxide surface. The double layer capacity was measured by cyclic voltammetry $[16,17]$.

\section{Results}

\subsection{Polarization characteristics}

Polarization curves for hydrogen evolution reaction taken on progressively improved electrocatalysts are shown in Fig. 1.

The beneficial effect of the addition of $\mathrm{TiO}_{2}$ to the Ni solelycontaining catalyst is visible from comparison of curves 1 and 2 (without and with $\mathrm{TiO}_{2}$, respectively). It accounts for $50 \mathrm{mV}$ lower hydrogen evolution overpotential at $60 \mathrm{~mA} \mathrm{~cm}^{-2}$ (adopted as reference c.d.). Further modifications applied to the catalyst's components, as e.g. thermal treatment of $\mathrm{TiO}_{2}$ at higher temperature, substitution of Vulcan XC-72 with MWCNTs and addition of cobalt into hyper d-phase (see Fig. 1. caption and Table 3) continually lower HER overpotential.

The system where all three components are substituted by modified ones (sample 7) appeared to show the most pronounced synergetic effect-with HER overpotential lower for $230 \mathrm{mV}$ as compared to the basic system (sample 2) or even $280 \mathrm{mV}$ with regard to the starting Ni-only catalyst (sample 1).

\section{Table 3}

Polarization characteristics of investigated electrocatalysts

\begin{tabular}{llc}
\hline Sample no. (see Table 2) & $\eta_{60}(\mathrm{mV})$ & $\Delta \eta$ (vs. basic catalyst) \\
\hline 1 & -535 & -50 \\
2 & -485 & 0 \\
3 & -425 & 60 \\
4 & -365 & 120 \\
6 & -290 & 195 \\
5 & -340 & 145 \\
7 & -255 & 230 \\
\hline
\end{tabular}

In order to produce sound explanation of the registered improvements in catalytic activity (Table 3, samples 1 toward 7) comprehensive structural and surface characterization has been made and is presented bellow.

\subsection{Structural characteristics}

XRD characteristics of the catalysts were presented elsewhere $[18,19]$. These catalysts contain a hyper d-metallic phase (Ni) of crystalline structure, the size of grains being 10-20 nm. In the mixed metallic system solid $\mathrm{Ni}-\mathrm{Co}$ solution was detected too, what means that part of the Co substitutes $\mathrm{Ni}$ atoms in $\mathrm{Ni}$ crystal lattice. Co "impurity" atoms substitute Ni host atoms in local Ni crystalline environment and simultaneously structural phase transition of Co from amorphous to crystalline (as a solidstate solution) occurs [20]. The rest amount of Co continues to be amorphous with size of grains lower than $2 \mathrm{~nm}$. Hypo doxide phase $\left(\mathrm{TiO}_{2}\right)$ treated at $250{ }^{\circ} \mathrm{C}$ was not detected by XRD, what means that $\mathrm{TiO}_{2}$ is amorphous. Rising the temperature of thermal treatment up to $480{ }^{\circ} \mathrm{C}$ contributes to transformation of $\mathrm{TiO}_{2}$ hypo d-oxide phase from amorphous to anatase crystalline structure with grain size of 7-8 $\mathrm{nm}$ [19].

\subsection{SEM analysis}

In Fig. 2 SEM microphotographies of four catalysts are shown. One can see, the catalyst's particles deposited on Vulcan are of a spherical shape. There is a grouping of the particles in clusters, whereat good adherence between particles is achieved. Presence of a numbers of holes between the aggregates is evident, thus contributing to the higher specific surface area, and consequently to a higher electrocatalytic activity. The size of clusters formed by deposition of $\mathrm{TiO}_{2}$ on Vulcan XC-72 is approximately $50-100 \mathrm{~nm}$ (Fig. 2a). The clusters of $\mathrm{Ni}$ deposited directly on Vulcan XC-72 (sample 1) are bigger, 100-150 nm (Fig. 2b), what means that Ni crystals of size 10-20 nm are larger than particles of $\mathrm{TiO}_{2}$. Due to amorphous character of $\mathrm{TiO}_{2}$ its size could not determine by XRD method. The clusters formed by deposition of $\mathrm{Ni}$ on support of Vulcan $\mathrm{XC}-72+\mathrm{TiO}_{2}$ become larger than previous ones, with size of 150-200 nm (Fig. 2c). Catalysts deposited on MWCNTs are with oriented structure (Fig. 2d). The particles of hypo d-oxide and hyper d-metallic phases grafted on MWCNTs are grouped in smaller clusters than those on Vulcan XC-72. This causes holes between particles to appear. Due to intrinsic geometrical features of MWCNTs (empty cylinders with higher developed surface area as compared to the spherical particles of Vulcan $\mathrm{XC}-72$ ), they possess inner holes and the inner porosity of MWCNTs is considerably higher than that of Vulcan XC-72. This is important for better dispersion of other components of the catalysts on the surface, especially active catalytic centers.

SEM analysis is not able to give any information on the nature of bonding (mechanical or chemical) of different particles into the catalyst's clusters. This information can be obtained by further spectroscopic investigation, by e.g. infrared spectroscopy or X-ray photoelectron spectroscopy (XPS), as shown bellow. 


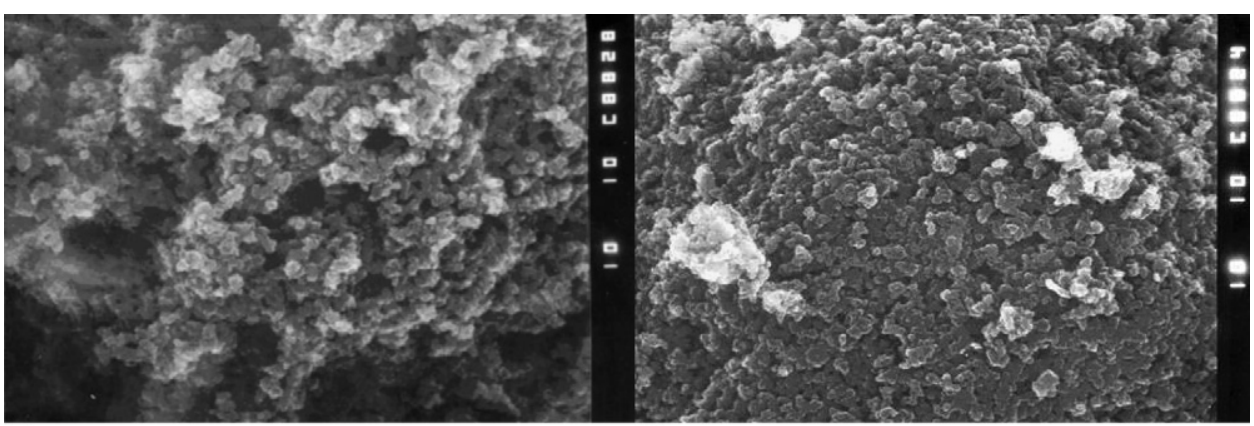

(a)

(b)

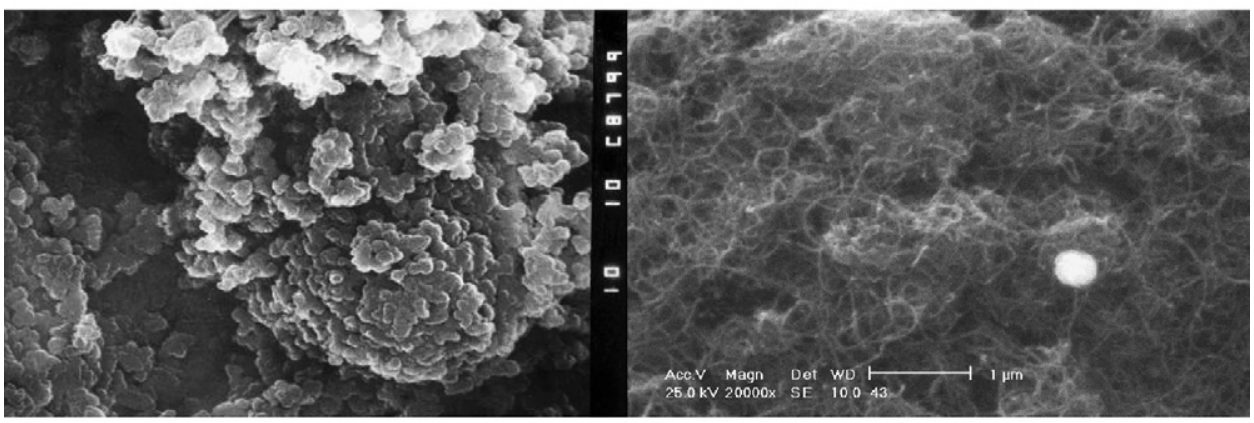

(c)

(d)

Fig. 2. SEM photographies of: (a) catalyst's support $\left(\mathrm{TiO}_{2}\left(250^{\circ} \mathrm{C}\right)\right.$ on Vulcan $\left.\mathrm{XC}-72\right), 10,000 \times$; (b) pure Ni deposited on Vulcan $\mathrm{XC}-72$ (sample 1$), 10,000 \times$; (c) basic hypo-hyper d-electrocatalyst (sample 2), 10,000×; (d) modified carbon substrate (sample 4), 20,000×.

\subsection{Infrared analysis}

On the FT-IR spectra of investigated catalysts the only band of interest originates by $\mathrm{TiO}_{2}$ [21]. To determine hypo-hyper d-interaction one has to compare $\mathrm{TiO}_{2}$ band from electrocatalyst and band from pure $\mathrm{TiO}_{2}$ obtained in identical conditions as that in electrocatalyst (Fig. 3). The band 1 in Fig. 3a originates from pure $\mathrm{TiO}_{2}$ obtained at $250{ }^{\circ} \mathrm{C}$, while bands 2 and 5 from $\mathrm{TiO}_{2}$ in electrocatalysts (samples 2 and 5). The peaks of the bands 2 and 5 are shifted to higher wave number related to the peak of pure $\mathrm{TiO}_{2}$. The higher the shift of wave number, the shorter the bond between $\mathrm{TiO}_{2}$ and hyper d-metallic phase, i.e. the higher the hypo-hyper d-interaction. This shift is about $50 \mathrm{~cm}^{-1}$ for both systems. This is an evidence for existence of hypo-hyper d-interaction what causes changes in adsorption characteristics of the electrode materials and synergetic electrocatalytic effect of for hydrogen evolution. $\mathrm{Ni}-\mathrm{TiO}_{2}$ and $\mathrm{NiCo}-\mathrm{TiO}_{2}$ interactions (Fig. 3a) are almost the same due to similar size of $\mathrm{Ni}$ and $\mathrm{Co}$ atoms. The band of $\mathrm{TiO}_{2}$ originated by modified electrocatalyst (sample 3 ) and corresponding band of pure $\mathrm{TiO}_{2}$ thermally treated at $480{ }^{\circ} \mathrm{C}$ and shown in Fig. 3b. The shift of peak of $\mathrm{TiO}_{2}$ in the catalyst is $120 \mathrm{~cm}^{-1}$ related to the peak of pure $\mathrm{TiO}_{2}$. This means that hypo-hyper d-interaction $\mathrm{Ni}-\mathrm{TiO}_{2}$ (anatase) is more than twice stronger than interaction $\mathrm{Ni}-\mathrm{TiO}_{2}$ (amorphous). It is expected the adsorption and catalytic characteristics for hydrogen evolution to be higher related to basic hypo-hyper d-electrocatalyst (sample 2). The shifts of $\mathrm{TiO}_{2}$ peaks for all catalysts, shown in Table 4, show that (a) intensity of hypo-hyper d-interaction depends on the thermal treatment of $\mathrm{TiO}_{2}$ and (b) the shifts are the same for catalysts with identical $\mathrm{Tio}_{2}$ treatment. These facts are important for further explanation of the changes produced by the studied modifications.

\subsection{XPS analysis}

In order to identify valence state of surface phases of the catalysts, XPS measurements were done. Analyzing the values of binding energy of Ti-spectra (Fig. 4a) one can conclude that peaks originated from $\mathrm{Ti} 2 \mathrm{p}_{3 / 2}$ and $\mathrm{Ti} 2 \mathrm{p}_{1 / 2}$ correspond to valence state $\mathrm{Ti}^{4+}$. The peaks are wide and non-symmetric, what means that they are produced by superposition of several elemental ones. This is due to the interaction between hypo d-oxide and hyper d-metallic phases. The values of binding energy of peaks of Ti2 $\mathrm{p}_{1 / 2}(465.0 \mathrm{eV})$ and Ti2 $\mathrm{p}_{3 / 2}(459.3 \mathrm{eV})$ correspond to table values of $\mathrm{TiO}_{2}\left(464.7 \mathrm{eV}\right.$ for $\mathrm{Ti} 2 \mathrm{p}_{1 / 2}$ and $459.2 \mathrm{eV}$ for $\left.\mathrm{Ti} 2 \mathrm{p}_{3 / 2}\right)$ [22]. The table value of $\mathrm{TiO}_{2} / \mathrm{TiNi}$ phase $\left(459.0 \mathrm{eV}\right.$ for $\left.\mathrm{Ti} 2 \mathrm{p}_{3 / 2}\right)$ imply a presence of some amount of this phase, what is reasonable due to the interaction $\mathrm{TiO}_{2}-\mathrm{Ni}$ detected by IR and XPS spectra.

Table 4

Differences of maximum values of wave number of $\mathrm{TiO}_{2}$ bands originated by electrocatalysts vs. corresponding ones of pure $\mathrm{TiO}_{2}$

\begin{tabular}{lc}
\hline Sample no. & $\Delta$ wave number $\left(\mathrm{cm}^{-1}\right)$ \\
\hline 1 & - \\
2 & 50 \\
3 & 120 \\
4 & 50 \\
6 & 50 \\
5 & 120 \\
7 & 120 \\
\hline
\end{tabular}



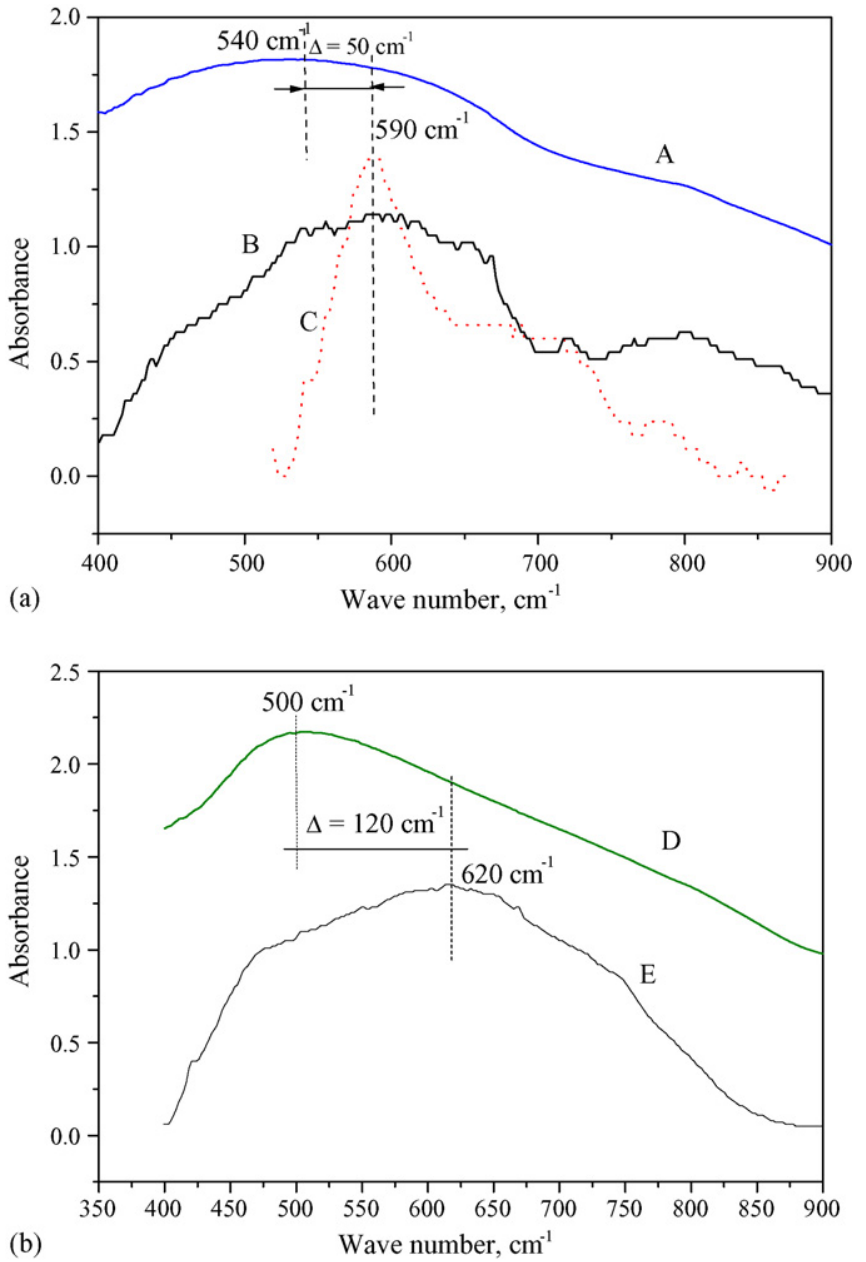

Fig. 3. Infrared spectra of $\mathrm{TiO}_{2}$ thermally treated at: (a) $250{ }^{\circ} \mathrm{C}$ and (b) $480{ }^{\circ} \mathrm{C}$. (A) Pure $\mathrm{TiO}_{2}$ treated at $250^{\circ} \mathrm{C}$; (B) $\mathrm{TiO}_{2}$ incorporated in the basic catalyst (sample 2); (C) $\mathrm{TiO}_{2}$ incorporated in the modified catalyst (sample 5); (D) pure $\mathrm{TiO}_{2}$ treated at $480{ }^{\circ} \mathrm{C}$; (E) $\mathrm{TiO}_{2}$ incorporated in the modified catalyst (sample 3).

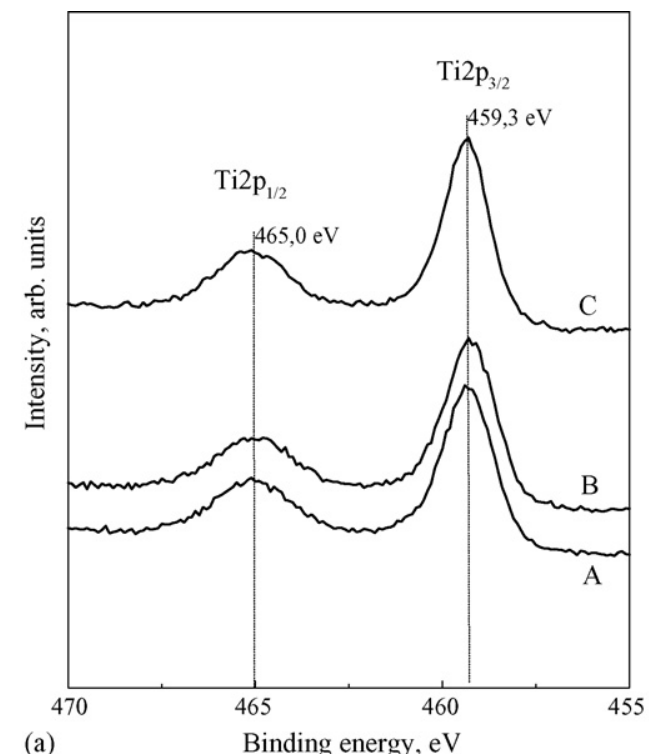

The peak of $\mathrm{Ni}_{2} \mathrm{p}_{3 / 2}$ spectra on position of binding energy of $856.6 \mathrm{eV}$ and satellite peak $\mathrm{Ni} 2 \mathrm{p}_{3 / 2 \text { (sat) }}$ on $862 \mathrm{eV}$ suggest an existence of $\mathrm{Ni}(\mathrm{OH})_{2}$ phase. This means that the main amount of $\mathrm{Ni}$ on the surface layer up to depth of several $\AA$ exists as $\mathrm{Ni}(\mathrm{OH})_{2}$. The small peak on position of $854.2 \mathrm{eV}$ indicates a presence of small amount of $\mathrm{NiO}$ with the same table value as the measured one, while the peak on position $853.1 \mathrm{eV}$ corresponds to presence of NiTi phase (table value of $853.15 \mathrm{eV}$ ). This is in accordance with the previous spectra of $\mathrm{TiO}_{2}$ phase as well as the IR spectra. The peak on position $852.4 \mathrm{eV}$ for the catalyst modified with adding of Co (sample 5) implies a presence of small amount of $\mathrm{NiCo}$ (table value $852.7 \mathrm{eV}$ ).

All these results suggest on hypo-hyper d-interaction as the considerable factor in improvement of catalytic characteristics of the investigated electrocatalysts.

\subsection{Real versus geometrical surface area}

To compare the level of surface roughness (the ratio of real versus geometrical surface area, $S_{\mathrm{R}} / S_{\mathrm{G}}$ ), the capacity of double layer $\left(C_{\mathrm{dl}}\right)$ of the catalysts was determined by cyclic voltammetry in the potential region where only charging of double layer occurs. Scan rates of $1-10 \mathrm{mV} \mathrm{s}^{-1}$ were applied. Current density of double layer charging $i_{\text {cap }}$ was adopted to be as an average value of anodic and cathodic current densities at potential at middle of the scanned interval. The plot of $i_{\text {cap }}$ as a function of scan rate shows straight-line dependence with a slope equal to the value of double layer capacity of the electrode surface:

$C_{\mathrm{dl}}=\frac{\mathrm{d} i_{\text {cap }}}{\mathrm{d}(\partial E / \mathrm{d} t)}$.

The values of double layer capacity and the ratio of real versus geometrical surface area of investigated catalysts are shown in Table 5. As can see, the surface area of all catalysts is highly developed, especially of those deposited on MWCNTs

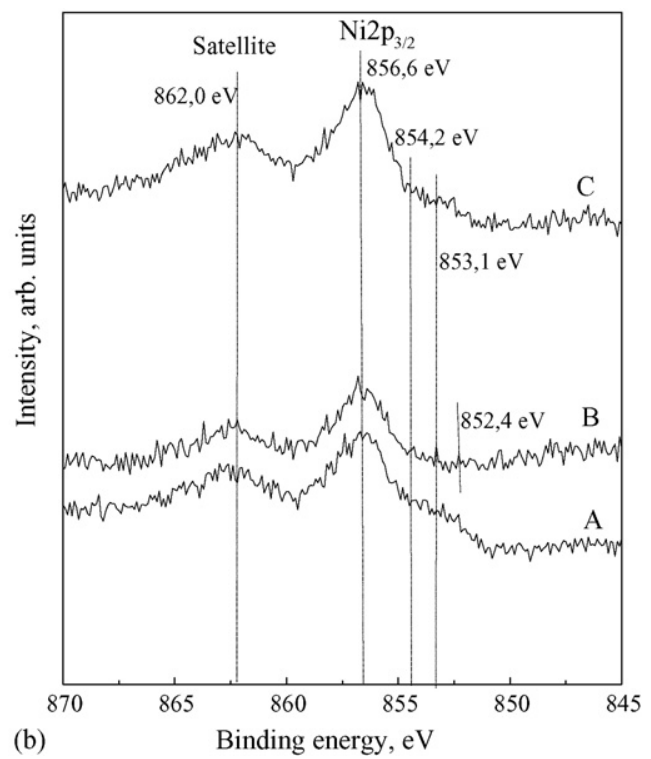

Fig. 4. XPS spectra originated by $\mathrm{Ti}^{4+}$ and $\mathrm{Ni}^{2+}$. (A) basic hypo-hyper d-electrocatalysts (sample 2); (B) modified hyper $d$-phase (sample 5); (C) modified hypo d-phase (sample 3). 
Table 5

Double layer capacity, $C_{\mathrm{dl}}$ and ratio of real vs. geometrical surface area, $S_{\mathrm{R}} / S_{\mathrm{G}}$

\begin{tabular}{lll}
\hline Sample no. & $C_{\mathrm{dl}}\left(\mathrm{mF} \mathrm{cm}^{-2}\right)$ & $S_{\mathrm{R}} / S_{\mathrm{G}}$ \\
\hline 1 & 16230 & 2705 \\
2 & 16000 & 2670 \\
3 & 16940 & 2820 \\
4 & 32551 & 5425 \\
6 & 15648 & 2610 \\
5 & 32663 & 5443 \\
7 & 30260 & 5043 \\
\hline
\end{tabular}

as a substrate. $C_{\mathrm{dl}}$ value of MWCNTs are almost twice higher than that of Vulcan XC-72 $\left(C_{\mathrm{d}(\mathrm{MWCNT})}=331 \mathrm{mF} \mathrm{cm}^{-2}\right.$ versus $C_{\mathrm{dl}(\mathrm{Vulc} \text { XC-72) }}=179 \mathrm{mF} \mathrm{cm}^{-2}$ ), what means that real surface area of MWCNTs is twice then the surface of Vulcan XC-72 [19]. The surface area of the catalysts deposited on MWCNTs is as well twice higher than those on Vulcan XC-72 (see Table 5). All catalysts deposited on Vulcan XC-72 (pure Ni (sample 1), basic hypo-hyper d-electrocatalyst (sample 2) and modified ones (samples 3 and 5) have approximately similarly developed surface area. NiCo-based catalysts (samples 5 and 7) in both cases deposited on Vulcan XC-72 and MWCNTs show some lower surface area than corresponding ones of Ni-based catalysts (samples 2, 4 and 6). Thermal treatment of $\mathrm{TiO}_{2}$ to $480^{\circ} \mathrm{C}$ also contributes to slight increase of surface area.

\section{Discussion}

\subsection{Basic hypo-hyper d-electrocatalyst}

Adding hypo d-oxide phase, $\mathrm{TiO}_{2}$, into hyper d-metal, $\mathrm{Ni}$, results in appearance of synergetic effect of electrocatalytic activity for hydrogen evolution reaction. This was confirmed with the analysis and discussion of the polarization curves shown in Fig. 1. Other proof that the improved activity is result of hypo-hyper d-interaction only was produced with IR spectroscopy (Fig. 3). Presence of $\mathrm{TiO}_{2} / \mathrm{TiNi}$ and $\mathrm{Ni}$ phase indicated by XPS analysis supports this conclusion. The ratio of real versus geometric surface area is almost the same for samples 1 and 2 (Table 5), what means that surface area effect is negligible, and that only an increase of intrinsic catalytic activity was achieved due to $\mathrm{Ni}-\mathrm{TiO}_{2}$ interaction. In this case hypo d-oxide phase $\mathrm{TiO}_{2}$ has bifunctional role, as a catalyst's support and as a participant in the overall synergetic effect, due to the "strong metal-support interaction" (SMSI). SMSI has been termed by Tauster et al. [23] to account for the changes in catalytic activity when metals of VIII group are supported on $\mathrm{TiO}_{2}$ in heterogeneous catalysis. Hypo d-phase changes electronic structure of hyper d-metal. These changes of electron structure and mutual sharing of d-orbitals provides electronic configuration suitable for $\mathrm{H}^{+}$adherence and transference [4]. The electron density near hyper d-metal is higher in the alloy than in a pure state, due to electron transfer from the surrounding atoms of hyper d-phase $[24,25]$. In this case, hydrogen evolution near the metal atoms should be favorized in the composite catalyst rather than in pure hyper d-metal.

\subsection{Modification of hypo d-oxide phase}

Transformation of amorphous titania in anatase crystalline form at $480^{\circ} \mathrm{C}$ contributes to higher activity of catalyst where this $\mathrm{TiO}_{2}$ is used. The overpotential for HER on the modified catalyst (sample 3 ) is for $60 \mathrm{mV}$ lower than on the basic catalyst and even $110 \mathrm{mV}$ lower than on pure $\mathrm{Ni}$ (see Table 3). Comparing $S_{\mathrm{R}} / S_{\mathrm{G}}$ values, one can see that modified catalyst has negligible higher surface area (only 5\%). IR analysis provides evidence that after heating at $480^{\circ} \mathrm{C}$ absorbance band maximum of $\mathrm{TiO}_{2}$ incorporated into the modified catalyst (sample 3) is shifted for $120 \mathrm{~cm}^{-1}$ as compared to the reference, pure $\mathrm{TiO}_{2}$ treated at the same temperature (see Fig. 3b). This shift is to be compared with a shift of only $50 \mathrm{~cm}^{-1}$ measured in the basic catalyst (Fig. 3a). This difference indicates that the measured increase of electrode's activity is a result of pure hypo-hyper $\mathrm{d}$-interaction between $\mathrm{Ni}$ and anatase, which is 2.4 times higher than in the basic catalysts. Thus, the SMSI is much stronger when anatase is used as a hypo d-oxide phase. The unique role of anatase form of titania in improvement of catalytic activity in both heterogeneous chemical catalysis and electrocatalysis has been noticed by other authors [26,27].

\subsection{Modification of carbon substrate}

Substitution of Vulcan XC-72 with MWCNTs as carbon substrate results in a decrease of HER overpotential for as much as $120 \mathrm{mV}$. This increase of the catalytic activity is of different character than the previous ones. Data presented in the Table 4 show that the mentioned carbon substitution does not change the level of hypo-hyper d-interaction. On the other side, the surface area of MWCNTs (sample 4) is almost twice higher than the one with Vulcan XC-72. This indicates that the increased activity of MWCNTs based catalysts is caused not by the rise of intrinsic electrocatalytic activity, but by increase of the elecrode's real surface area.

The higher activity for hydrogen evolution is a result first of all of the nature of carbon nanotubes. Their inner structure, surface area and conductive characteristics are favorable for used MWCNTs as a carbon substrate for the nanostructured electrocatalysts. Their high developed surface area enables better dispersion of active catalytic centers across the catalyst's surface. Also, extra-conductive properties enable easier electron exchange with hydrogen protons, what intensifies formation of adsorbed hydrogen atoms and further hydrogen molecules. On the other side, its high inter- and trans-particle porosity as well as its geometry (empty cylinders), do facilitate the escape of hydrogen molecules from catalyst's surface.

\subsection{Modification of hyper d-metallic phase}

Addition of cobalt into metallic phase in atomic ratio $\mathrm{Ni}: \mathrm{Co}=1: 1$, shows remarkable increase of catalytic activity for HER. This is surprising because: (a) according to the IR results the hypo-hyper d-interaction is not affected by addition of Co (Fig. 3a), (b) the real surface area of the modified catalyst is even lower than the referent one (See Table 5). The same is 
situation with the ratio of BET surfaces (basic versus modified catalyst $=108: 96 \mathrm{~m}^{2} \mathrm{~g}^{-1}$ ), (c) $\mathrm{Ni}$ and $\mathrm{Co}$, as individual metals, exhibit similar activity for HER [28]. So, the question arises on what is the reason why addition of $\mathrm{Co}$ into $\mathrm{Ni}$ causes such a remarkable activity increase?

The answer lays in the similarity of NiCo-based catalyst with the systems that contain Co only [29].

The XRD analysis, as well as the results presented elsewhere $[18,20]$ indicates that $\mathrm{Co}$ in this case exists in two different phases. A minor part of it forms a Ni-Co solid-state solution, while the rest continues to exist as pure (amorphous) Co with size of particles lower than $2 \mathrm{~nm}$. So, involving Co into metallic phase considerably increases the real surface area of active catalytic centers. Also, there is better dispersion of metallic catalytic centers, what means that whole catalyst's surface is available for hydrogen evolution reaction. Instead of that, although basic catalyst has a higher surface area, its crystalline particles are bigger $(10-20 \mathrm{~nm})$, so the real surface area of active catalytic centers is considerably lower. Dispersion of these larger particles is less uniform what means that no whole catalyst's surface is available for hydrogen evolution.

\subsection{Complete modification}

Ni-based catalyst with completely modified support (sample 6) shows high decrease of overpotential for HER, i.e. $145 \mathrm{mV}$ as compared to the basic electrocatalyst. The improved activity for hydrogen evolution is a result of both intrinsic hypo-hyper $\mathrm{d}$-interaction between $\mathrm{Ni}$ and anatase and increasing of the real surface area. As discussed above, the higher contribution in the total effect has the increase of surface area caused by introduction of MWCNTs.

The completely modified catalyst (sample 7) was shown to perform the best one of all investigated series. Overpotential for hydrogen evolution is even $230 \mathrm{mV}$ lower than that of basic electrocatalyst. The ratio of hydrogen evolution current densities at $\eta=-250 \mathrm{mV}$ is $6 \mathrm{~mA} \mathrm{~cm}^{-2}$ versus $60 \mathrm{~mA} \mathrm{~cm}^{-2}$, indicating that completely modified catalyst performs 10 times faster hydrogen evolution. This remarkable activity improvement is result of three phenomena: hypo-hyper d-interaction, increase of surface area of the catalyst as a whole and high surface area of hyper d-metallic phase as an active catalytic center. The order of their contribution has an opposite order: the most effective is the involving of Co into hyper d-metallic phase.

On the end, one should mention that three-dimensional gasdiffusion electrodes could possibly acquire lower activity at higher current densities (as compared to, e.g. Raney-Ni or Raney-Ni activated electrodes) due to the nature of their structure. If evolved hydrogen could not escape out of the subcritically sized pores, then the operating surface area (of such 3D electrodes) is lower than the real one. Similar phenomenon was found and discussed by Wendt and co-workers [30,31]. According to them even as much as $90 \%$ of the surface area available for hydrogen evolution could be blocked and become inactive. Probably the similar is situation with our electrodes. Engineering aspects of the electrodes are planed to be subject of study in some further stages, and are not included in this paper. The aim of this research is to improve catalytic behavior of the investigated composite material.

\section{Conclusion}

The investigations in this study were motivated by the idea to obtain nanostructured composite non-platinum electrocatalysts for hydrogen evolution. So, hypo-hyper d-electrocatalysts based on Ni were prepared and tested. The basic hypo-hyper delectrocatalyst has shown a synergetic effect, i.e. higher activity than that of pure $\mathrm{Ni}$ obtained in the same conditions.

Further modifications consist of: (i) transformation of amorphous $\mathrm{TiO}_{2}$ into anatase crystalline form, (ii) substitution of carbon substrate (Vulcan XC-72) with carbon nanotubes and (iii) introducing of Co into metallic phase. The very choice of these modifications is not at all occasional, but is rather based on some previous experiences and results achieved by such and/or similar options. This is why all three modifications appeared to be successful.

The effect of converting $\mathrm{TiO}_{2}$ from amorphous into crystalline one results in decreasing of the overpotential for $60 \mathrm{mV}$.

The effect of use of MWCNTs instead of Vulcan XC-72, was very successful. The overpotential decreases for $120 \mathrm{mV}$ as compared to the basic electrocatalyst.

Finally, the addition of $\mathrm{Co}$ in atomic ratio $\mathrm{Ni}: \mathrm{Co}=1: 1$ lowers the overpotential even for $195 \mathrm{mV}$.

Completely modified catalyst performed the best for HER, lowering overpotential for remarkable $230 \mathrm{mV}$ compared with the basic hypo-hyper d-electrocatalyst.

The highest contribution in improvement of catalytic behavior for HER was attributed to the addition of Co into metallic phase, the resulting rise of the active catalytic centers surface area, next was the effect of MWCNTs as a carbon substrate, due to increase of real surface area of the catalyst as a whole and finally is intrinsic hypo-hyper d-interaction.

Finally, one could conclude that the investigated catalytic systems are rather complex and one could practically never state that the best of their performance is achieved. Modifications like this (or other) will probably be further visioned and applied, just contributing to further, steep or slow, but no matter continuous increase of the catalytic activity for the HER.

\section{Acknowledgements}

This paper has been supported by and carried out within the EU Project "PROMETHEAS" PL ICA2-2001-10037 and Project 13-1650/4-02 of Ministry of Education and Science of Republic of Macedonia.

Special thank to the staff of the "Institute of Electrochemistry and Energy Systems", Bulgarian Academy of Science, Sofia for the fruitful collaboration and the hospitality in the Academy's laboratories during investigation.

Thank to Dr. Vladimir Ivanovski, University "Sts. Cyril and Methodius" for the help in IR measurements as well as analysis and commentary of results. 


\section{References}

[1] E.W. Brooman, A.T. Kuhn, J. Electroanal. Chem. 49 (1974) 325.

[2] L. Brewer, Science 161 (1968) 115.

[3] M. Jakšić, V. Komnenić, R. Atanasoski, R. Adžić, Electrokhimiya 13 (1977) 1355.

[4] M.M. Jakšić, Int. J. Hydrogen Energy 12 (1987) 727.

[5] M.M. Jakšić, Č.M. Lačnjevac, B.N. Grgur, N.V. Krstajić, J. New Mater. Electrochem. Syst. 3 (2000) 169.

[6] I. Paseka, Electrochim. Acta 40 (1995) 1633.

[7] L. Chen, A. Lasia, J. Electrochem. Soc. 138 (1991) 3321.

[8] S. Trasatti, G. Lodi, Properties of conductive transition metal oxides with Rutile-type structure, in: S. Trasatti (Ed.), Electrodes of Conductive Metallic Oxides Part A, Elsevier Scientific Publishing Company, 1980, p. 301.

[9] E. Veggetti, I.M. Kodintsev, S. Trasatti, J. Electroanal. Chem. 339 (1992) 255.

[10] B. Borresen, E. Rasten, G. Hagen, R. Tunold, Hydrogen evolution on $\mathrm{Ru}_{x} \mathrm{Ti}_{1-x} \mathrm{O}_{2}$, in: Proceedings of the Third International Symposium on Electrocatalysis, Portorož, Slovenia, 1999, p. 186.

[11] M.M. Jakšić, Solid State Ionics 136-137 (2000) 733.

[12] S.G. Neophytides, S.H. Zafeiratos, M.M. Jakšić, J. Electrochem. Soc. 150 (2003) E512.

[13] C. Roth, M. Goetz, H. Fuess, J. Appl. Electrochem. 32 (2001) 793.

[14] R.M. Abouatallah, D.W. Kirk, S.J. Thorpe, J.W. Graydon, Electrochim. Acta 47 (2001) 613.

[15] BG Patent Appl. No. 38581.

[16] B. Marsan, N. Fradette, Beaudoin, J. Electrochem. Soc. 139 (1992) 1889.
[17] L.M. Da Silva, L.A. De Faria, J.F.C. Boodts, Electrochim. Acta 47 (2001) 395.

[18] S. Hadži Jorddanov, P. Paunović, O. Popovski, A. Dimitrov, D. Slavkov, Bull. Chem. Technol. Macedonia 23 (2004) 101.

[19] P. Paunović, O. Popovski, S. Hadži Jordanov, A. Dimitrov, D. Slavkov, J. Serb. Chem. Soc. 71 (2) (2006) 149-165.

[20] Y.L. Soo, et al., Appl. Phys. Lett. 81 (2002) 655.

[21] P. Paunović, Electrocatalysis of hydrogen evolution reaction: system based on $\mathrm{Ni} / \mathrm{TiO}_{2} / \mathrm{C}, \mathrm{Ph}$.D. Thesis, University "Sts. Cyril and Methodius", Skopje, 2005, p. 96

[22] http://srdata.nist.gov/xps.

[23] S.J. Tauster, S.C. Fung, R.L. Garten, J. Am. Chem. Soc. 100 (1978) 170

[24] H. Ezaki, M. Morinaga, S. Watanabe, Electrochim. Acta 38 (1993) 557

[25] H. Shibutani, T. Higashijima, H. Ezaki, M. Morinaga, K. Kikuchi, Electrochim. Acta 43 (1998) 3235.

[26] S.J. Tauster, S.C. Fung, J. Catal. 55 (1978) 29.

[27] S.G. Neophytides, S. Zaferiatos, G.D. Papakonstantnou, J.M. Jakšić, F.E. Paloukis, M.M. Jakšić, Int. J. Hydrogen Energy 30 (2005) 131.

[28] H. Kita, J. Electrochem. Soc. 113 (1966) 1095.

[29] P. Paunović, et al., $\mathrm{Co} / \mathrm{TiO}_{2}$ hypo-hyper d-catalyst for hydrogen evolution reaction (HER), in: Proceedings of the XVIIIth Congress on the Chemists and Technologists of Macedonia, Extended Abstracts, [ECH-3], Ohrid, September 2004, p. 23.

[30] S. Rausch, H. Wendt, J. Electrochem. Soc. 143 (1996) 2852.

[31] Th. Borucinski, S. Rausch, H. Wendt, J. Appl. Electrochem. 22 (1992) 1031. 